\title{
A CIDADE E O ENSINO DE GEOGRAFIA significação a partir das práticas espaciais cotidianas
}

Hugo de Carvalho Sobrinho ${ }^{1}$

Resumo: A presente reflexão tem como objetivo destacar a temática da cidade e sua relação com a construção dos conhecimentos geográficos, fazendo considerações sobre os sujeitos e as suas práticas espaciais no cotidiano. A metodologia utilizada para elaboração desse trabalho baseia-se numa perspectiva qualitativa, e a pesquisa bibliográfica apoia-se, fundamentalmente, nas considerações de autores que pesquisam as temáticas. A partir disso, direciona-se o olhar a respeito da cidade sobre o prisma do ensino da Geografia e, assim, são estabelecidas associações para perceber a possibilidade de conduzir à significação de conteúdos e, por conseguinte, à construção da aprendizagem. Depreende-se que é necessário fazer da cidade uma via de compreensão das práticas espaciais dos sujeitos e possibilitar a significação no processo de ensinar/aprender Geografia.

Palavras-chave: Cidade. Sujeitos. Práticas Espaciais. Significação.

\section{THE CITY AND THE GEOGRAPHY TEATCHING meaning from daily spaces practices}

\begin{abstract}
The present research aims to highlight the theme of the city and its relation with the construction of the geographical knowledge, making considerations about the subjects and their space practices in the daily life. The methodology used to elaborate this work is based on a qualitative perspective, and the bibliographical research is based, fundamentally, on the authors arguments who research the city theme and the Geography teaching. In this perspective, the view of the geography teaching is directed towards it, and thus, associations are established to understand the possibility of leading to the meaning of contents and, consequently, to the construction of learning. It is necessary to making the city a way of understanding the space practices of the subjects and to make possible the meaning in the process of teaching/learning Geography.
\end{abstract}

Keywords: City. Subjects. Space practices. Meaning.

\author{
$[\ldots]$ \\ E a cidade se apresenta \\ Centro das ambições \\ Para mendigos ou ricos \\ E outras armações \\ Coletivos, automóveis, \\ Motos e metrôs \\ Trabalhadores, patrões, \\ Policiais, camelôs
}

\footnotetext{
${ }^{1}$ Doutorando e Mestre em Geografia pela Universidade de Brasília (UnB) na área de concentração em Gestão Territorial e Ambiental. Professor da Carreira do Magistério Público da Secretaria de Estado de Educação do Distrito Federal - SEEDF. Integra o grupo de pesquisa - Ensino, Aprendizagem e Formação de Professores em Geografia da Universidade de Brasília - GEAF/UnB. E-mail: hugo.carvalhosobrinho@gmail.com
} 
A cidade não para

A cidade só cresce

O de cima sobe

E o de baixo desce

A cidade se encontra Prostituída

Por aqueles que a usaram

Em busca de uma saída

Ilusora de pessoas

De outros lugares,

A cidade e sua fama

Vai além dos mares

Chico Science (1994)

\section{INTRODUÇÃO}

Ao escolher como meio inspirador e instigador a epígrafe acima, trago à tona, as reflexões que permeiam a discussão de tantos geógrafos e professores dedicados à Geografia Escolar. Questões que se relacionam com os movimentos que pulsam na cidade. Tais ponderações apontam para a relevância da Educação Geográfica no sentido de refletir e valorizar esses elementos na construção de conhecimentos geográficos. Constituição de um movimento que esteja a serviço da superação de tantas dificuldades. A canção critica os problemas que assolam as cidades. Assim, tal fato evidencia que elas são constituídas por espacialidades cotidianas que merecem atenção no processo pedagógico tanto na valorização de seus elementos, como na busca de superação daqueles que estão a serviço da segregação espacial.

De tal modo, o cotidiano sempre foi permeado por práticas espaciais, a partir disso, reconhecemos que a ciência geográfica, em seus processos de investigação, voltase para a análise, o conhecimento e a compreensão das espacialidades vividas em contextos diferenciados da dinâmica da vida social (MORAIS; CAVALCANTI, 2011). É nesse sentido que a Geografia é um campo do conhecimento que se direciona a compreensão da realidade e da complexidade do espaço geográfico.

O tema cidade ${ }^{2}$, no período atual, é objeto de novas reflexões, pois se apresenta como um espaço privilegiado das práticas cotidianas de diferentes sujeitos e contextos. Ela possui elementos da vida cotidiana que não podem passar despercebidos, tais como a

\footnotetext{
2 A opção por refletir a questão da significação das práticas espaciais cotidianas na/da cidade está relacionada ao recorte teórico. Não há intenção de menosprezar ou mesmo diminuir o campo, pois sabemos que também se constitui lugar de significar as vivências e experiências com os fenômenos geográficos.
} 


\section{REVISTA ELETRÔNICA \\ DA GRADUAÇÃO/PÓS-GRADUAÇÃO EM EDUCAÇÃO UFG/REJ}

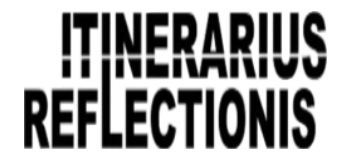

ISSN. 1807-9342

Volume 14, N. 2, 2018

mobilidade, as condições de moradia, a exclusão espacial, os deslocamentos diários, a utilização do espaço urbano, as manifestações culturais, as tecnologias, o trabalho, as rugosidades e, ao mesmo tempo, as novas configurações na estrutura das cidades entre outros. De tal modo, diversos pesquisadores de variadas áreas do conhecimento se voltam para sua análise, na medida em que seus elementos se tornaram objetos de estudos, sendo considerada, por muitos, como via de formação das pessoas e da sociedade em geral. Nessa perspectiva, a presente reflexão pensa a cidade como um lugar de formação, em decorrência da sua complexidade e dos fenômenos geográficos que aí se manifestam (CAVALCANTI, 2008).

Nossa intenção volta-se, principalmente, à possibilidade da Geografia Escolar destacar a cidade, dimensão espacial concreta, e sua relação com a construção dos conhecimentos geográficos, permitindo, assim, fazer considerações sobre os sujeitos e as suas práticas espaciais no cotidiano da vida urbana vivida e experimentada na cidade. Ao decorrer do texto, faremos uso, em determinados momentos, de exemplos do Distrito Federal, que se constitui o nosso lugar de fala e de análise.

\section{CONSIDERAÇÕES SOBRE A DINÂMICA DA CIDADE: as práticas espaciais cotidianas}

No cenário globalizado contemporâneo, em que o processo de urbanização constitui uma das principais características, de tal maneira a cidade assume um caráter relevante. No caso do Brasil, por exemplo, as cidades abrigam aproximadamente $84 \%$ da população brasileira (IBGE, 2018), sendo marcadas por forte multiculturalismo e diversos modos de convívio urbano, que, de certo modo, enriquecem a vida cotidiana e as manifestações que aí se materializam. É nesse sentido que Cavalcanti (2008) afirma que a cidade se constitui como os lugares de encontros e de diferenças, que são ricas e relevantes para a prática espacial cotidiana. As cidades podem ser consideradas como centros da vida social, onde se acumulam não apenas as riquezas produzidas, mas também conhecimentos e cultura. Há uma infinidade de ações e objetos produzidos pelos seres humanos, o que origina uma espacialidade bastante complexa e contraditória (LEVEBVRE, 1991). 


\section{REVISTA ELETRÔNICA \\ DA GRADUAÇÃO/PÓS-GRADUAÇÃO EM EDUCAÇÃO \\ UFG/REJ}

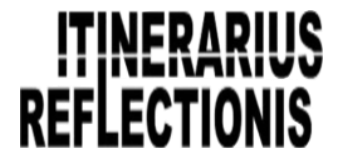

ISSN. 1807-9342

Volume 14, N. 2, 2018

Ao analisar a definição de cidade de Harvey, Corrêa (2001) pondera que essa é uma forma de organização do espaço pelo homem, bem como uma expressão concreta de processos sociais na forma de um ambiente edificado sobre os meios geográficos. Para o autor, existem modeladores da organização do espaço, que são os proprietários dos meios de produção, os donos da terra, as empresas do grande capital e o próprio Estado, o que, naturalmente, exclui grande parte da sociedade no que diz respeito aos usufrutos dessa organização, devido à própria dinâmica do modo capitalista de produção, que tem como base o processo terra-capital-trabalho que intensificou o processo de urbanização. Analisando mais detidamente essa dinâmica, pode-se indagar se a cidade de Brasília, com os elementos apontados anteriormente, apresenta-se como uma cidade que promoveu, desde a suas origens, a segregação social. É uma questão latente em nosso cotidiano, posto que, ao percorrer a capital federal, observa-se que ela mesma expressa uma dinâmica que, ao longo dos anos, produziu uma periferia da produção da cidade, áreas pobres e sem infraestrutura, como, por exemplo, a cidade de Ceilândia - DF, onde se localiza uma das maiores áreas periféricas da América Latina.

Nesse sentido, a cidade cresce bruscamente em sua superfície total e o fenômeno da especulação segue o mesmo ritmo. Morar na periferia da cidade é o destino dos pobres, que são condenados a não dispor de serviços sociais ou utilizá-los precariamente (SANTOS, 2000). É nesse cenário que as sociedades, prioritariamente nas cidades, convivem com sonhos e pesadelos.

Os múltiplos significados dos espaços vividos, sobreposição de representações, exige uma nova abordagem. A região, cidade, bairro, espelho das nossas sociedades, são ambos os sonhos e pesadelos. O geógrafo estuda para se tornar um interlocutor válido face aos tecnocratas do desenvolvimento e dos teóricos do desenvolvimento de cima. Sem integrar a riqueza das relações íntimas humanas-simbólicas dos lugares, a Geografia desencantada perde seu saber geográfico (BAILLY; SCARIATI, 2001, p. 219, tradução nossa).

Pelo viés da Geografia, percebe-se, assim, que a cidade também é um lugar de injustiças sociais, onde os bairros com rendas mais baixas são os menos equipados (SCARLATO, 2011). Tuan (2012) também faz essa reflexão em relação aos status sociais diferentes, evidenciando que as partes separadas da cidade geram a segregação social. De acordo com o autor, as cidades são as estruturas materiais mais complexas que o homem 


\section{REVISTA ELETRÔNICA \\ DA GRADUAÇÃO/PÓS-GRADUAÇÃO EM EDUCAÇÃO \\ UFG/REJ}

\section{TrEERPUS \\ REFLECTIONIS}

ISSN. 1807-9342

Volume 14, N. 2, 2018

já construiu e correspondem a um ambiente radicalmente transformado.

Em consequência, a cidade é mais do que as materializações das relações sociais e de produção, é todo um modo de viver, pensar e sentir (CARLOS, 2013). É complexa e abriga uma infinidade de modos de vida. Ela é ativa, não deve ser pensada ou mesmo visualizada como algo inerte, mas sim como um espaço que está vivo (DARDEL, 2011). Como destaca Sposito (2013), para entendê-la não basta apenas observá-la ou nela viver, mas é necessário a verificação de sua dinâmica, de sua História e Geografia, que contemplam os variados processos que a produzem e a caracterizam, frutos de conteúdos e formas manifestadas, ao longo do tempo, no espaço.

A partir disso, vislumbram-se muitas possibilidades de se pensar a cidade sob o prisma do habitar e da construção de conhecimentos, por meio dos objetos, ações e relações que tomam lugar nela. Para Lefebvre (1991), a cidade envolve o habitar por meio do local em que se constitui a vida privada, ponto de partida e chegada. Dessa forma, é necessário considerar as relações imediatas, o cotidiano, o inconsciente, os problemas, por se constituir um espaço com múltiplos significados e que abriga variados conceitos. Ressaltamos, assim, que a cidade a ser considerada neste ensaio é uma dimensão do vivido, logo, esfera e lugar da vida que pode ser utilizada para a construção de conhecimentos significativos no ensino de Geografia. A partir dessa consideração, apontamos que, nos últimos anos, várias pesquisas têm assinalado a necessidade de se refletir sobre a cidade como objeto de estudo no ensino da Geografia (BENTO 2011; CASTELLAR, 2009; CAVALCANTI, 2008; OLIVEIRA, 2015; SILVA, 2016). Tais pesquisas evidenciam que os conteúdos e conceitos geográficos devem considerar a cidade no processo de sistematização dos conhecimentos geográficos. De tal modo,

A cidade é também assunto de preocupação dos estudiosos da área de educação escolar, como os que se dedicam ao estudo do ensino de Geografia, pois não se trata apenas de um conteúdo específico a ser veiculado na escola, em diferentes níveis, mas é também parte das tarefas de formação da cidadania, em sentido mais abrangente, a serem cumpridas por ela (CAVALCANTI, 2008, p. 7-8).

Fazer da cidade uma via de compreensão da realidade é possibilitar o processo de significação no processo de ensinar/aprender Geografia, ou seja, das práticas espaciais cotidianas. Os alunos precisam compreender as várias dimensões, enfoques e arranjos espaciais da cidade, para que assim possam construir conhecimentos que serão aplicados 


\section{REVISTA ELETRÔNICA \\ DA GRADUAÇÃO/PÓS-GRADUAÇÃO EM EDUCAÇÃO \\ UFG/REJ}

\section{ITINEPRARIIUS \\ REFLECTIONIS}

ISSN. 1807-9342

Volume 14, N. 2, 2018

no seu lugar vivido, como via de compreensão dessa realidade. Há de se considerar, ainda, que o próprio currículo escolar destaca a cidade e o lugar de vivência como um dos temas que estruturam a análise geográfica. Nesse sentido, a cidade passa a ser pensada não somente como um conteúdo a ser transmitido pela Geografia, mas como um instrumento de consciência cidadã, de vivência e de ensino/aprendizagem.

Todas as cidades educam, na medida em que a relação do sujeito, do habitante, com esse espaço é de interação ativa e dialética e trazer essa experiência, real e cotidiana, como parte integrante da ação pedagógica, leva a eficácia do processo de aprendizagem a um patamar superior (CASTELLAR; VILHENA, 2010, p. 127).

Nessa perspectiva, a cidade, enquanto um dos lugares de vivência, pode ser significada pelos professores em seus diversos espaços e tempos para a construção do conhecimento em Geografia. Nas palavras de Cavalcanti, "A cidade é educadora: ela educa, ela forma valores, comportamentos, ela informa com sua espacialidade, com seus sinais, com suas imagens, com sua escrita. Ela também é um conteúdo a ser apreendido por seus habitantes" (CAVALCANTI, 2008, p. 74).

Ter a cidade como objeto de estudo geográfico é estudar os seus sistemas de entradas e saídas; suas vias de acesso em vários pontos; as inte-relações com as aglomerações populacionais; a dinâmica econômica e cultural de seus moradores - que gera características particulares dos bairros; as relações socioambientais que se estabelecem; o quadro da saúde pública; em suma, os diversos elementos que compõem a paisagem do lugar (CASTELLAR; VILHENA, 2010, p. 123).

É importante destacar que tais considerações atestam que a Geografia não se restringe aos conhecimentos referentes à localização espacial, mas se volta para a exploração do espaço da vida e dos homens como meio social. É nesse sentido que a cidade deve ser explorada para fins pedagógicos e sociais; o aluno, ao conhecer sua cidade e por meio dos exemplos e situações aí existentes, poderá construir conceitos e conhecimentos para ampliar sua visão acerca do mundo. Carlos (2004) corrobora tal ideia ao considerar que:

A cidade, mais do que a materialidade das relações sociais de produção, é todo um modo de viver, pensar e sentir. Ela é o lugar privilegiado do urbano, fenômeno que em parte existe na vida cotidiana das cidades e, ao mesmo tempo, está posto em sua totalidade, sendo parte de um 


\section{REVISTA ELETRÔNICA \\ DA GRADUAÇÃO/PÓS-GRADUAÇÃO EM EDUCAÇÃO UFG/REJ}

\section{ITWERMUU REFLECTIONIS}

ISSN. 1807-9342

Volume 14, N. 2, 2018

processo em constituição na sociedade, ainda não realizado em todas as suas possibilidades (p. 135).

Por consequência, assume-se que o estudo da cidade seja profícuo para práticas escolares, posto que nela ocorrem a maioria dos múltiplos eventos, que são importantes para a prática da cidadania. A esse respeito, Castellar (2010, p. 45) afirma que "a aprendizagem será significativa quando a referência do conteúdo estiver presente no cotidiano da sala de aula, quando se considerar o conhecimento que a criança traz consigo, a partir de sua vivência". Em consequência, pode-se concluir que cidade e lugar unem-se para resultar num aprendizado significativo, que avance na perspectiva de compreensão do espaço geográfico. De acordo com Cavalcanti (2002),

[...] a cidade considerada conteúdo escolar não é concebida apenas como forma física, mas como materialização de modos de vida, como um espaço simbólico, formador de sentidos de pertinência e de identidade fundamental para a formação da cidadania. Sendo assim seu estudo volta-se para desenvolver no aluno a compreensão do modo de vida da sociedade contemporânea e de seu cotidiano em particular (p.75).

Ao levar em conta o caráter socioeducativo das cidades, Cavalcanti (2008) propõe uma metodologia para sua análise, que perpassa a identificação de suas áreas comerciais e residenciais, seu centro histórico, sua morfologia, seu perfil socioeconômico e demográfico, as áreas de ocupação irregular, conflitos e contradições, as dimensões culturais de seus habitantes, suas características naturais, entre outros. Tal sugestão metodológica, porém, exige do professor um conhecimento mínimo sobre o lugar como condição para que ocorram os processos de mediação pedagógica. Portanto, é necessário que os professores não somente estejam atentos e compreendam que, por meio dos espaços vivenciados e experimentados pelos alunos no dia a dia, é possível tanto uma condução de aprendizagem significativa, como também, e principalmente, que conheçam a cidade/lugar que mediará a construção coletiva do conhecimento geográfico. Assim, ao valorizar a cidade e as cotidianidades dos alunos, os professores contribuirão para sua inclusão no processo de aprendizagem, construindo conhecimentos.

Mediante breve observação da Geografia do Distrito Federal, por exemplo, é possível perceber as variadas dinâmicas que pulsam nas diferentes cidades que compõem 


\section{REVISTA ELETRÔNICA \\ DA GRADUAÇÃO/PÓS-GRADUAÇÃO EM EDUCAÇÃO UFG/REJ}

\section{ITIMERARIIUS REFLECTIONIS}

ISSN. 1807-9342

Volume 14, N. 2, 2018

a estrutura urbana dessa unidade da federação. Grande parte das áreas periféricas ${ }^{3}$ do Distrito Federal ainda carece de infraestrutura básica: saneamento básico, segurança, saúde, asfalto, educação, entre outros. Principalmente nas escolas que fazem parte dessa rede educacional, tais dinâmicas, que compõem o cotidiano vivido dos sujeitos, devem ser consideradas no processo de significação de conteúdos no ensino/aprendizagem de Geografia.

É importante ratificar que a cidade possui inúmeros espaços públicos para a realização da vida pública, o que se apresenta como um caminho para subsidiar a formação para a cidadania, conforme explicitado anteriormente. Em uma reflexão sobre espaço público e a cidade, Silva (2016) afirma que

Os espaços públicos na cidade deveriam cumprir esse objetivo de ser o local da reunião, do encontro, o locus privilegiado da realização da vida pública. A escola pública teria, do mesmo modo, também essa função de reunir diferentes pensamentos, culturas, sujeitos, além de ter como pauta os conhecimentos sobre cidade como forma de subsidiar a formação cidadã (p. 165).

Nessa linha de pensamento, Bento (2011) considera que

A cidade, por sua vez, inscreve-se também na escola, contra a pretensão homogeneizadora escolar, a cidade se lhe apresenta continuamente como uma experiência do heterogêneo e do múltiplo. A cidade se impõe à escola como pluralidade de sujeitos, de culturas, de instituições, de estímulos, de sensibilidades, ou seja, como uma experiência de aprendizagem muito diversificada [...] (p. 80).

Se a cidade está inserida em uma multiplicidade de fenômenos e diversidade, a consideração desses aspectos faz com que a escola busque exercer a sua função principal: formar o cidadão. Propõe-se, assim, que a cidade seja analisada enquanto espaço vivido do aluno; que se faça uso de seus espaços para a promoção de uma proposta pedagógica enraizada na realidade; que seja aproveitada pelos docentes para a realização de propostas educativas; que possibilitem uma aprendizagem mais significativa; que permita aos sujeitos sociais a compreensão de sua própria capacidade de transformar a sua cidade, e, por meio dela, produzir e reproduzir o espaço.

\footnotetext{
${ }^{3}$ Aqui entendida como áreas pobres, desvalorizadas e esquecidas por parte do poder público.
} 


\section{REVISTA ELETRÔNICA \\ DA GRADUAÇÃO/PÓS-GRADUAÇÃO EM EDUCAÇÃO UFG/REJ}

\section{ITIMERARIIUS REFLECTIONIS}

ISSN. 1807-9342

Volume 14, N. 2, 2018

As considerações efetuadas convergem para apresentar a cidade e a sua vinculação com as práticas cotidianas como elementos fundamentais para o processo de ensinoaprendizagem de Geografia, por promoverem uma dinâmica relacional que resulte na compreensão da espacialidade. Nessa perspectiva, a grandeza dos fenômenos da cidade contribui para o aprendizado de forma dinâmica, pois possibilita a relação entre os conteúdos ministrados nas salas de aula e os conhecimentos dos próprios alunos. Ao entender que a sociedade é parte permanente do ato de educar, o professor deve conduzir seus alunos e mediar os conhecimentos ensinados buscando ir ao encontro do mundo vivido dos educandos. Isso pode começar, por exemplo, pela exploração dos espaços que rodeiam a escola, dos percursos casa-escola, entre outras possibilidades, desde que conduzam os alunos a perceber, conhecer, intervir e (re)criar a sua cidade.

Assim, a cidade abriga fenômenos geográficos, cotidianos e globais, que podem ser significados para a construção e sistematização dos conhecimentos geográficos, por meio das vivências e experiências dos alunos com esses fenômenos em seu cotidiano. $\mathrm{O}$ espaço que é vivido é, sem dúvida, uma forma de engajar os alunos na ação transformadora do seu espaço. Para Castellar (2009),

Estudar a cidade enquanto lugar de vivência exige conhecermos as histórias dos lugares, as condições em que se inserem, tanto do ponto de vista do quadro natural, quanto das condições sociais e políticas e das diferenciações culturais. Cada cidade apresenta marcas que lhe são características, mas cada cidade também responde a questões globais, externas a essa região, e que precisam ser consideradas tanto na perspectiva do global quanto na do local (p. 105).

As questões aqui salientadas podem ser percebidas e observadas no próprio movimento da cidade, por meio de seus sujeitos. A compreensão da lógica dos movimentos, que são vivenciados e experimentados pelos alunos no seu espaço vivido, mediada pelos professores, permitirá ao aluno aproximar-se do exercício ativo da cidadania, no sentido de compreender que suas marcas são peculiares e globais ao mesmo tempo.

A apreensão da cidade requer o conhecimento espacial. Outro exemplo atrelado ao nosso lugar de fala é a consideração de que os professores de Geografia do Distrito Federal necessitam ter conhecimento dos elementos que compõem a estrutura urbana e 


\section{REVISTA ELETRÔNICA \\ DA GRADUAÇÃO/PÓS-GRADUAÇÃO EM EDUCAÇÃO \\ UFG/REJ}

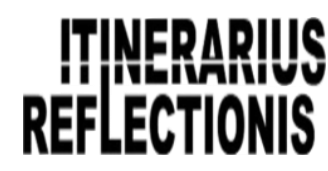

ISSN. 1807-9342

Volume 14, N. 2, 2018

os da cidade para promover a mediação e internalização dos conhecimentos geográficos que são importantes para as práticas espaciais dos sujeitos.

Esse conhecimento deve se estender de forma particular e articulada nas variadas e diferentes cidades. Entender o relevo, a rede de drenagem, o solo, a degradação ambiental, as ocupações irregulares, a segregação urbana, a crise hídrica, a arquitetura das cidades, entre tantos outros temas, é condição necessária para a mediação pedagógica. É fundamental formar para a vida cidadã, ter a compreensão do que o ser cidadão significa, entender essas dinâmicas para ter uma postura crítica, ativa, participativa, aberta e transformadora (CAVALCANTI, 2008).

\section{CONSIDERAÇÕES FINAIS}

As questões aqui cunhadas podem ser observadas e analisadas no movimento da cidade ou do próprio bairro, espaços que são vividos pelos sujeitos em suas variadas dimensões, inclusive a simbólica. É necessário compreender a complexidade de conteúdos e conceitos que envolvem o tema cidade e saber estabelecer conexões reais a partir do vivido pelos sujeitos em suas práticas espaciais.

Depreende-se que é imprescindível utilizar o lugar, nesse caso a cidade, como uma via de compreensão das práticas espaciais dos sujeitos e possibilitar a significação no processo de ensinar/aprender Geografia. Durante as reflexões, somadas às de outros pesquisadores, referimo-nos eventualmente ao Distrito Federal, por ser este nosso lugar de fala, mas é necessário que cada docente, em suas diferentes cidades, reconheça a sua geografia para que os elementos sejam significados aos estudantes e sujeitos. Defendemos que a cidadania ativa perpassa o conhecimento da geografia local, de forma a (re)conhecer nela os conceitos e conhecimentos e, assim, propor soluções para que os problemas sejam resolvidos ou mesmo amenizados.

A Geografia Escolar manifesta sua preocupação com os problemas que envolvem a cidade e tem buscado metodologias que possibilitem que os sujeitos e suas práticas espaciais sejam pontos de saída e chegada para a compreensão das dinâmicas complexas da sociedade contemporânea. Portanto, tal fato evidencia que as elas são constituídas por espacialidades que merecem atenção no ensino de geografia tanto na valorização de seus 


\section{REVISTA ELETRÔNICA \\ DA GRADUAÇÃO/PÓS-GRADUAÇÃO EM EDUCAÇÃO \\ UFG/REJ}

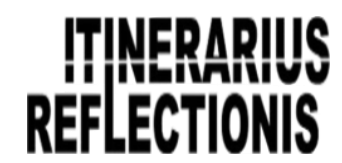

ISSN. 1807-9342

Volume 14, N. 2, 2018

elementos, como na busca de superação daqueles que estão a serviço da segregação espacial.

\section{AGRADECIMENTOS}

Agradeço ao do Grupo de Pesquisa Ensino, Aprendizagem e Formação de Professores em Geografia da Universidade de Brasília (GEAF-UnB) pelos momentos de reflexões durante a enlevada deste trabalho.

\section{REFERÊNCIAS}

BAILLY, A. SCARIATI, R. L'humanisme en géographie. In: BAILLY, Antoine. Les concepts de la géographie humanine.Paris: Armand Colin,p.213-222, 2001.

BENTO, I. P. Estudar a cidade e seus sujeitos para aprender Geografia. In: MORAIS, Eliana Marta Barbosa de; CAVALCANTI, Lana de Souza (Orgs.). A cidade e seus sujeitos. Goiânia: Editora Vieira, 2011. p. 71-88.

CARLOS, A. F. A. O espaço urbano: novos escritos sobre a cidade. Ed. Contexto, 2004.

Cidade. São Paulo: Contexto, 2013.

CASTELLAR, S. M. V. Educação Geográfica: Formação e didática. In: MORAIS, E. M. B.; MORAES, L. B. (Orgs.). Formação de professores: conteúdos e metodologias no ensino de Geografia. Goiânia: Nepeg, 2010.

" "Lugar de Vivência: a cidade e a aprendizagem". In: Garrido,

Marcelo. (Org.). Reflexiones sobre eles pacioenel mundo educativo. Reflexiones sobre el espacioenel mundo educativo. 1ed. Santiago: Ediciones Universidad Academia de Humanismo Cristiano, 2009, p. 37-56.

CASTELLAR, S. M. V. VILHENA, J. Ensino de Geografia. Cengage Learning, 2010.

CAVALCANTI, L. S. Geografia e práticas de ensino. Goiânia: Alternativa, 2002. . A Geografia escolar e a cidade: Ensaios de Geografia para a vida urbana cotidiana. Campinas, SP: Papirus, 2008.

CORRÊA, R. L. Espaço: um conceito-chave da Geografia. In: CASTRO, Iná Elias de; GOMES, Paulo Cesar da; CORRÊA, Roberto Lobato (orgs.). Geografia: conceitos e temas. Rio de Janeiro: Bertrand Brasil, p. 15-47, 2001.

DARDEL, E. O homem e a terra: natureza da realidade geográfica; tradução Werther Holzer. - São Paulo: Perspectiva, 2011. 
REVISTA ELETRÔNICA

DA GRADUAÇÃO/PÓS-GRADUAÇÃ̃ EM EDUCAÇÃO

UFG/REJ

\section{ITHEPAPIIS \\ REFLECTIONIS}

ISSN. 1807-9342

Volume 14, N. 2, 2018

HARVEY, D. A Condição Pós-Moderna. São Paulo: ed. Loyola, 1992.

INSTITUTO DE BRASILEIRO DE GEOGRAFIA E ESTATÍSTICA - IBGE. Goiás; Formosa. Disponível: 〈http://cidades.ibge.gov.br/xtras/perfil.php?codmun=520800>. Acesso em: 20 de março. 2018.

LEFEBVRE, H. O direito à cidade. Tradução de Rubens Eduardo Frias. São Paulo: Editora Moraes, 1991.

MORAIS, E. M. B. CAVALCANTI, L. S. A cidade e seus sujeitos. Goiânia: Editora Vieira, 2011.

OLIVEIRA, L. O ensino/aprendizagem de Geografia nos diferentes níveis de ensino. In: PONTUSCHKA, Nídia Nacib; OLIVEIRA, Ariovaldo Umbelino de. Geografia em perspectiva: ensino e pesquisa. São Paulo: Contexto, 2015.

SANTOS, M. O espaço do cidadão. 5 ed. São Paulo: Studio Nobel, 2000.

SCARLATO, F. C. População e urbanização brasileira. In: ROSS, R. L. S. Geografia do Brasil. São Paulo: Edusp, p. 381 - 463, 2011.

SILVA, A. B. A Geografia do espaço escolar: jovem-aluno, práticas espaciais e aprendizagem geográfica. 2016. $238 \mathrm{f}$. Tese (Doutorado em Geografia) - Instituto de Estudos Socioambientais, Universidade Federal de Goiás, Goiânia, 2016.

SPOSITO, E. S. A vida nas cidades. São Paulo: Contexto, 2013, 90 p.

TUAN, Yi-Fu. Topofilia: um estudo da percepção, atitudes e valores do meio ambiente. Londrina, PR: Eduel, 2012. 